\title{
Development of Two Positions and Two Channels Grease Valve Driven by Stepper Motor
}

\author{
Liping YUAN, Yugang ZHAO*, Xinyu LIU, Zhanjun WANG \\ School of Mechanical and Electrical Engineering of Shandong Jianzhu University \\ Jinan Shandong, 250101, China \\ E-mail:545360445@qq.com; *E-mail:zhaoyg9289@126.com \\ $+*$ Corresponding author
}

\begin{abstract}
A design scheme of two positions two channels grease valve driven by stepper motor was proposed, and the design of valve core and driving device was introduced. This scheme used stepping motor as the driving, and the thrust was greatly increased, and it was able to work stably under 40MPa. The two positions two channels valve spool in using, not required of the laying of oil return pipeline, reduced the cost of the system, and was able to form a stable back pressure. The clip and tighten pressure of the valve core was effectively reduced by using a pressure reducing groove. Through the test of the nominal pressure, nominal flow, pressure loss and maximum allowable back pressure, it is shown that the designed two positions two channels grease valve driven by stepper motor can effectively improve the reliability of intelligent grease centralized lubricating system, and it can improve the safety of lubrication equipment.
\end{abstract}

Keywords-grease valve; centralized grease; lubricating system; stepper motor

\section{GUIDELINES}

Intelligent grease centralized lubrication system has been widely used in port machinery, mining machinery and other large equipment by the oiling is convenient, save grease, seal good antirust property, easy to realize automatic lubrication[1]. The overall structure of the intelligent grease centralized lubricating system is shown in Fig. 1. The dry oil valve is the key equipment in the intelligent centralized lubrication system, it play the role of control circuit switch in the lubricating system. At present, two position four way solenoid valve as a style of dry oil valve has been widely used in the intelligent dry oil centralized lubricating system. Two position four way solenoid valves exposed a lot of defects in the application process. For example: two position four way solenoid valve need to lay the oil return pipeline in normal use, this increase the cost of system; The phenomenon of grease solidification is occurs frequently in the oil pipeline during using the dry oil lubrication system, causes action resistance of valve core increase, valve core was action failure caused by the thrust of electromagnet was not enough to overcome the resistance valve core. If the two position four way solenoid valve cannot break through the solidified grease effectively in the open valve condition, when the oil pipeline pressure relief after the valve closed, which cannot form a back pressure and not conducive to realizing lubrication. Considering the inefficiencies above, technical staff have put forward an improved method to obstructed an oil outlet of two position four way solenoid valve in the lubrication system and an oil returning hole is connected with the another oil outlet. This method has achieved some success in the application of lubrication system below 20MPa, which effectively worked out the problem of return pipeline and reduced costs, and the oil outlet can form a certain back pressure, which is conducive to the realization of lubrication. However, this approach still cannot meet the demand of lubrication system for $40 \mathrm{MPa}$ high pressure. In addition, when it is applied under the cold environment in our northeast regions, the failure rate of this method is higher; this phenomenon which the valve cannot be moved often occurs[2-3].

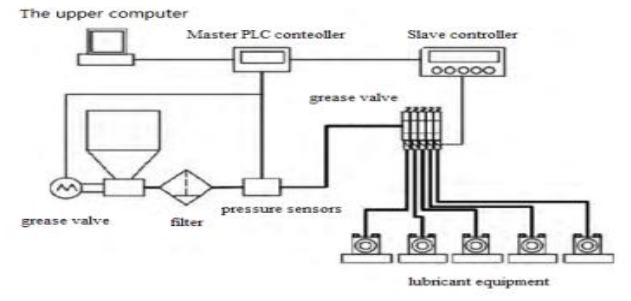

Figure 1. The diagram of intelligent centralized grease lubrication system

In this paper, the author in view of the shortcomings of grease valve in the intelligent grease centralized lubricating system, a design scheme of two positions two channels grease valve driven by stepper motor was presented, which can effectively improve the reliability of whole performance grease centralized lubricating system.

\section{The Overall Design Scheme of Grease VAlve}

In view of the shortcomings of grease valve in the intelligent grease centralized lubricating system, in this paper, the author put forward a scheme of two positions two channels grease valve driven by stepper motor. This scheme adopts step motor as the driver, and the thrust was greatly increased than the thrust of solenoid valve, and it was able to work stably under $40 \mathrm{MPa}$. Using the two positions two channels valve spool does not need to lay the oil return pipeline, reduced the cost of the system, and is able to form a stable back pressure, and is conductive to the realization of lubrication.

Fig. 2 is a diagram illustrating a structural of two positions two channels grease valve driven by stepper motor. 
This grease valve adopted the sliding valve structure form, which is mainly composed of the components such as power system, transmission system, valve body, valve core, sealing element etc. There are only two oil ports on the body (oil inlet and outlet), which adopting the seal way that clearance seal and Y-type seal combine together between valve core and valve body. The output shaft of the stepper motor is a trapezoidal screw, trapezoidal lead screw combined with trapezoidal nut, and flexible connection is used between trapezoidal nut and valve core, there is a key on the axial direction of nut, and a Key-Slot on the connecting block, The trapezoidal nut is sliding and cannot rotate in the inner hole of the connecting block, through the thrust of screw pair amplifying function, making trapezoidal nut move forward and backward ,also driving spool move, thus would be open and close the oil-way[4].

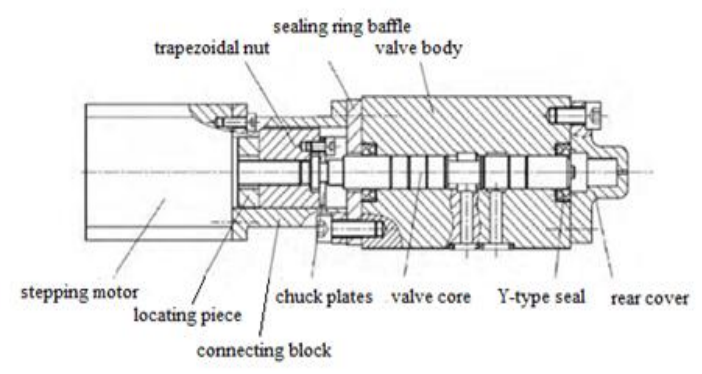

Figure 2. Structural diagram of the grease valve

\section{Design of Main Component of Grease VAlVE}

\section{A. Design of the Valve Core and Analysis of the Clamping Force}

When core and hole of slide valve are not concentric or shoulder is not vertical in valve hole, as a result, the distribution of oil is uneven alone the radius, and produces tightening force. Due to the existence of clamping force, will make the force required to move the valve core increase more, may even the valve core was jammed caused by lack of thrust [5].The author carried out a fluent simulation of two different valves models which are with or without rectangular balance groove, and optimization design on valve core. Fig 3 shows the computation geometric model for the tightening force of valve core. One piece of valve core length $\mathrm{L}=10 \mathrm{~mm}$ that should be taken as the study object, the angle of valve core: $\alpha=0.03^{\circ}$, the clearance between valve core and valve body: $\mathrm{c}=0.01 \mathrm{~mm}$, standard basic hole, valve hole radius: $\mathrm{R}=5 \mathrm{~mm}$, valve core radius: $\mathrm{r}=4.99 \mathrm{~mm}$. Both the depth and the width of the Pressure Equalizing Groove are $0.8 \mathrm{~mm}$.

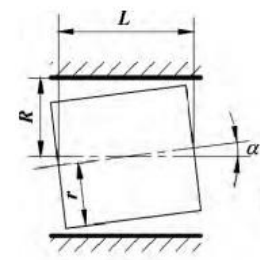

(a)

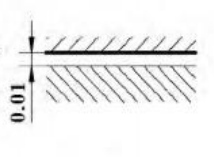

(b)

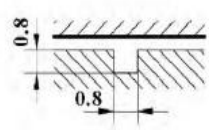

(c)
Figure 3. The geometric model
This thesis selects the grease between valve cores and valve sheath as the research object. Firstly, design a three-dimensional modeling for the product by using UG. Secondly, import the three-dimensional modeling into GAMBIT, and mesh the model, considering that the gap between the valve core and valve hole and the size of the Pressure Equalizing Groove is very different, so we use the solution of gridding meshing. And then we make the divided gridding model into MSH format [5]. Loading gridding file by using of Fluent, identify boundary condition, the Pressure-inlet is $40 \mathrm{MPa}$ and the Pressure-outlet is 0 , set the fluid density $\rho=920 \mathrm{~kg} / \mathrm{m} 3$ and similar viscosity $\mu=800$ $\mathrm{Pa} \cdot \mathrm{s}$.

In order to simplify simulation calculation, suppose oils without any impurities; ignore fluid gravity and heat exchange of internal valve chamber; assume that the fluid is not compressible Newtonian fluid [7-8].

Fig. 4 and 5 shows the pressure distribution of without pressure-balanced groove valve's wall and pressure distribution of valve core's upper and lower symmetric plane.
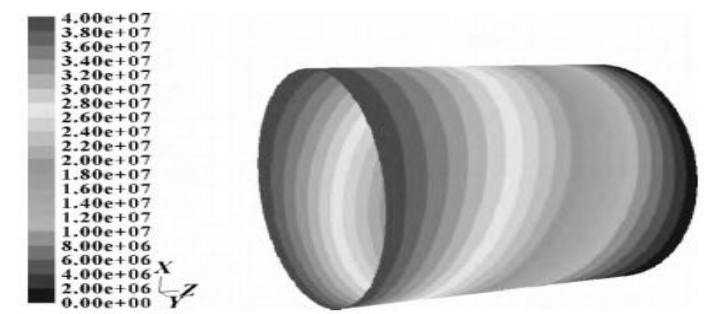

Figure 4. Stress contours of the spool without pressure grooves

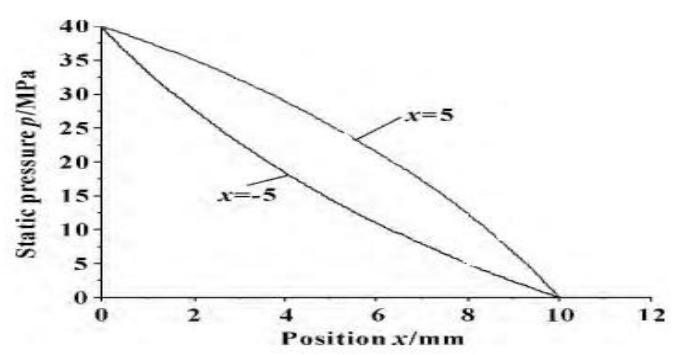

Figure 5. Pressure of the upper and lower symmetry plane of the spool without pressure grooves

We can see that pressure along $\mathrm{Z}$ direction is not well-distribution while there is not balance groove or valve cores tilt. On the entrance to the upper symmetric plane, the gap is larger while pressure decreased quickly. On the entrance to the lower, the gap is small while pressure decreased slowly. The situation between upper and lower is opposite. Upper and lower symmetric plane's pressure curve likes fusiform, and the area of fusiform represents imbalance force of valve core on radial direction.

Fig. 6 and 7 show the pressure distribution of pressure-balanced groove valve core's wall and the pressure distribution of valve core's upper and lower symmetric plane. It shows that pressure divided into 3-section along $\mathrm{Z}$ direction and each section like fusiform shape while there are 2 rectangular pressure-balanced grooves. At 
pressure-balanced groove, the pressure of upper and lower plane is equilibrium; seen from Fig. 7, the 3-section Hammer-shaped area is successively increasing from the entrance to the exit, each section generates more clamping force, but the total area of 3-section is much more smaller when it compares to the Fig. 5 which doesn't have any pressure-balanced groove, according to this situation, we know that pressure-balanced groove can reduce the clamping force effectively.
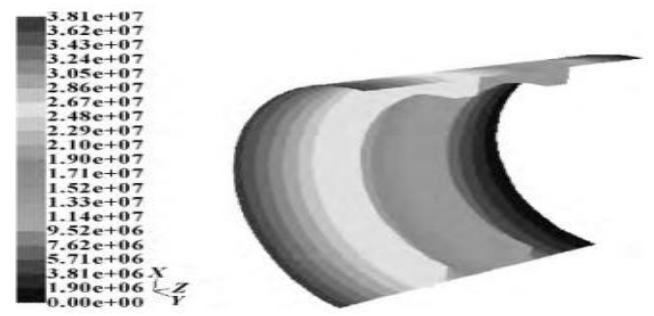

Figure 6. Stress contours of the spool with pressure grooves

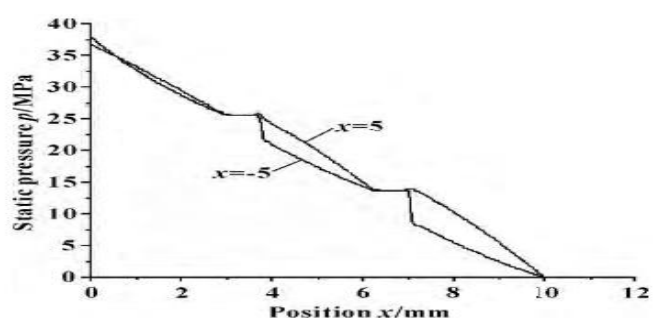

Figure 7. Pressure of the upper and lower symmetry plane of the spool with pressure grooves

The analysis of Fluent shows that pressure-balanced groove can reduce the clamping force of valve core, as a result, we designed more pressure-balanced groove on dry oil valve core, shown in the $3 \mathrm{D}$ model of Fig. 8. There is a lead tank in the central of the valve core, the lead tank make a connection between oil inlet and outlet during the valve is opening; on the left of valve core, there is a connecting raised-platform, the valve core and nut are flexible connection due to the raised-platform, this connection can provide that the valve core and hole is not affected by the tolerance of radial direction during fit, and make sure the precision.

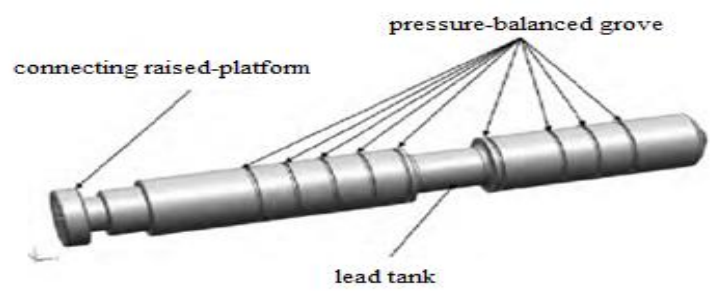

Figure 8. The 3D model of spool

\section{B. Design of the Drive Means}

Drive design is the keyword to the dry oil valve as it shown in the Fig. 9, the design of driving scheme: Power source is 24VFour-wire two-phase stepper motor, its maximum static torque of $0.32 \mathrm{~N}$.m; Stepper motor output shaft is a lead of $2 \mathrm{~mm}$ trapezoidal transmission wire bar, trapezoidal lead screw combined with trapezoidal nut, the nut has a guide on ladder, there is a guide groove in the hole of connection block, trapezoidal nut is sliding forward and backward in the hole. Since the valve body and core's precision is far greater than the precision of trapezoidal screw and nut, so trapezoidal nuts and valve using the flexible connection. Nut end surface is designed a hole with a diameter greater than the diameter of the core raised-platform, the depth equal to the height of the raised-platform. During assembling, put the valve core raised-platform into the hole of nut, and use the card to fix core on the nut, the core can move radial relatively but not axial movement. This design not only ensures precision fit valve core and body, but also to ensure that the positional accuracy of the core's movement.

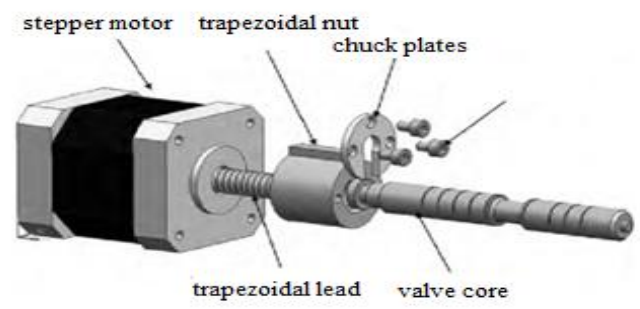

Figure 9. The 3D model of driver unit

Stepper motor force calculation:

$$
F=\frac{T \times 2 \mathrm{~T} \times P}{L}
$$

Where: $\mathrm{F}$ is a stepping motor maximum thrust; $\mathrm{T}$ is a stepping motor static torque, $\mathrm{T}=0.32 \mathrm{~N} \cdot \mathrm{m} ; \mathrm{P}$ is the screw efficiency, $\mathrm{P}=0.85, \mathrm{~L}$ is length of lead screw, $\mathrm{L}=2 \mathrm{~mm}$.

By the formula (1) can be calculated by the stepping motor maximum thrust of $854 \mathrm{~N}$, while the ordinary $24 \mathrm{~V}$ hydraulic electromagnet's maximum thrust is $70 \mathrm{~N}$ around. Therefore, using the stepping motor as a driving force can improve drive capability greatly, further, since the reversing of the stepping motor, we delete the return spring which shows in the hydraulic electromagnet. Due to no return spring, so there is no need to against spring force, this further improves the reliability.

\section{The ExPerimental Test of Dry OIL Valve PERFORMANCE}

Dry oil valve's characteristic including nominal pressure, nominal flow, pressure loss and maximum allowable back pressure. Nominal pressure is a sign of dry oil valve can afford stress; nominal flow is a sign of dry oil valve's mass flow rate under nominal pressure; pressure loss means the pressure difference between the inlet and outlet, which represents the impediment of the media through dry oil valve; allowed back pressure refers to the dry valve in the closed state and the oil outlet pipe can be connected in order to keep the maximum pressure. Allow back pressure is special requirements to dry oil valve in intelligent dry oil lubrication system. Allow back pressure is determined by the condition 
of internal vent, as well as by the viscosity and cone penetration affect the flow of oil [9].

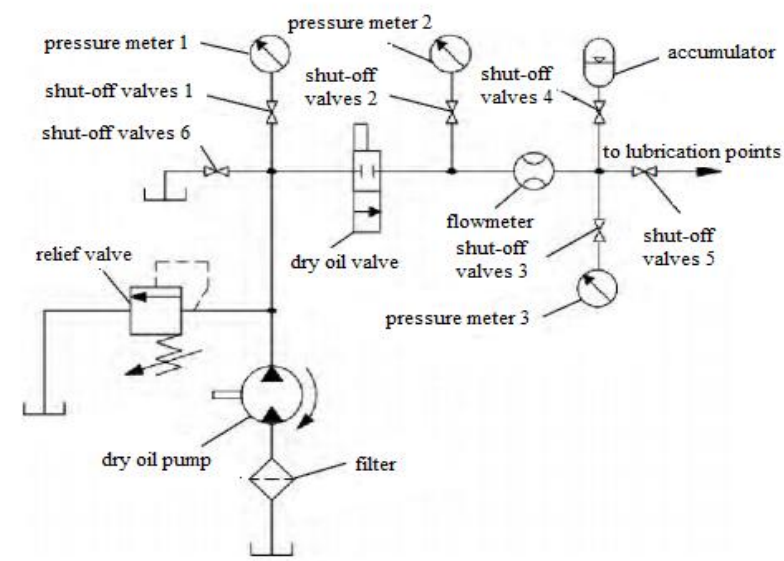

Figure 10. Diagram of performance testing plan

Fig. 10 is a dry oil valve performance testing protocols schematic. The test selected ZPU series of dry oil pump, the working pressure is $40 \mathrm{MPa}$, test medium selected by cone penetration of $265^{\prime}$ 's 2 \# lubricated cream $\left(25^{\circ} \mathrm{C} 150 \mathrm{~g}, 1 / 10\right.$ $\mathrm{mm}$ ), test temperature is $25^{\circ} \mathrm{C}$, and air relative humidity is 85\%.Testing performance parameters are shown in Table I.

TABLE I. Performance PARAMETERS OF GREASE VAlVE

\begin{tabular}{cccc}
\hline $\begin{array}{c}\text { nominal } \\
\text { pressure }\end{array}$ & $\begin{array}{c}\text { nominal } \\
\text { flow }\end{array}$ & $\begin{array}{c}\text { pressure } \\
\text { loss }\end{array}$ & $\begin{array}{c}\text { maximum allowable back } \\
\text { pressure }\end{array}$ \\
\hline $40 \mathrm{MPa}$ & $2 \mathrm{~L} / \mathrm{min}$ & $1.5 \mathrm{MPa}$ & $20 \mathrm{MPa}$ \\
\hline
\end{tabular}

From Table I, we know that designed dry oil valve could function well under pressure of $40 \mathrm{MPa}$ and it can also generate back pressure which is under $20 \mathrm{MPa}$, this is convenient to system lubrication; the nominal flowrate of valve is $2 \mathrm{~L} / \mathrm{min}$ when it's under $40 \mathrm{MPa}$ pressure, the pressure lost is $1.5 \mathrm{MPa}$, which is satisfied with the practical engineer requirement.

\section{CONCLUSION}

1) Proposed taking a stepping motor as the driving forces of the two-position two-way dry oil valve, and designed the connecting mean between dry oil valve core and the stepper motor.

2) Design pressure-balanced groove on valve core, according to fluent analysis, pressure-balanced groove could reduce core's clamping force dramatically.

3) The selected stepper motor driving force is much larger than solenoid driving force in the solenoid valve, and the design of the core return via stepper motor normal-reverse reaction, this design avoid the resistance of return spring during the valve operation in original solenoid valve, as a result, it improved the reliability of the valve.

\section{REFERENCE}

[1] Dong Changlei. Working principle of grease central lubricating system and its application [J].Construction Machinery, 2003 (8):52-54.

[2] Zhao Jingyi, Cao Wenao, Wang Biao,etal. Analysis and design of $80 \mathrm{t}$ slag pot carrier centralized grease-lubricating system [J].Lubrication Engineering, 2010, 30 (10):115-117.

[3] Wang Li, Su Bo. Research of intelligent centralized lubrication system and its development [J].Industrial Automation, 2010 (5):8-11.

[4] Yang Shuxing, Wang Shengjie, Yao Xiaoxian. Design of electric valve [J].Hydraulic and Pneumatic, 1997 (3):5-7.

[5] Liu Shuyin,Yang Shudong,Wu Liang,et al. Optimization design of the valve body strength and fit clearance for a large diameter spool valve[J]. Hydraulic and Pneumatic, 2012 (5):90-94.

[6] Jiang Jun, GuoYuan, ZengLiangcai, etal. Simulation and analysis of leakage for clearance seal of hydraulic cylinder [J]. Lubrication Engineering, 2013, 38 (7): 75-79.

[7] Jiang Guojin, YinChenbo, JiaWenhua, etal. Study on the effect of spool's microscopic surface on micro-flow in valve-gap [J]. Lubrication Engineering, 2011, 36 (5): 68-71.

[8] LuoYanlei, WuJianxing, Chen Lunjun, etal. The research of the pressure-equalizing groove for hydraulic slide valve based on CFD [J]. Hydraulics Pneumatics \& Seals, 2013, 33 (1):13-15. 